\title{
ARREST OF EARLY CARIOUS LESIONS AFTER PROFESSIONAL APPLICATION OF DIFFERENT FLUORIDE AGENTS
}

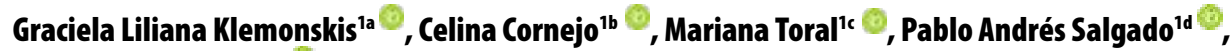 \\ Aldo Fabián Squassi ${ }^{1 \mathbf{e}^{*} \text { (2) }}$
}

${ }^{1}$ Chair of Department of Preventive and Community Dentistry, Faculty of Dentistry, University of Buenos Aires, Buenos Aires, Argentina

aDDS, PhD, Associated Professor; b, DDS; 'dic. Biol. Sc., Associated Proffesor; ' $D D S$, PhD, Chairman

ABSTRACT DOI: https://doi.org/10.25241/stomaeduj.2020.7(1).art.2

Objective: To compare the effectiveness of three professionally applied fluoride agents in arresting early carious lesions in young permanent teeth.

Methods: Aquasi-experimentalstudywasperformed.Eligiblepopulation:Schoolchildren aged 5-7 years presenting at least one permanent molar with early active carious lesion. Sample: 107 dental surfaces with early occlusal carious lesions (lesion code=1-2; activity code=2 -ICDAS II criteria-). Study design: (1) Baseline diagnosis, performed by 2 researchers (Kappa inter-observer: 0.8). (2) Application of a protocol for cariogenic infection control. (3) Participant assignment to groups: matched according to complexity of treatment needs at baseline: Group 1(G1) 5\% NaF varnish Duraphat ${ }^{\circledR}$ ( $n=53$ ); Group 2 (G2) 5\% $\mathrm{NaF}$ varnish containing $\beta$-TCP tricalcium phosphate $(n=33)$ Clinpro White Varnish $^{\circledR}$; Group 3 (G3) resin-modified glass ionomer cement varnish Clinpro XT Varnish ${ }^{\circledast}(n=19)$. (4) Single professional application of a fluoride agent. (5) Caries assessment 1 year post-treatment. Statistical analysis. The frequency of (a) early caries lesion remineralization one year post-treatment and (b) carious lesions that remained active but showed no progression 1 year post-treatment were calculated. Chi-Square and proportion comparison tests for independent

OPEN ACCESS This is an Open Access article
under the CC BY-NC 4.0 license.
Peer-Reviewed Article
Citation: Klemonskis GL, Cornejo C, Toral M, Salgado PA,
Squassi AF. Arrest of early carious lesions after professional
application of different fluoride agents.
Stoma Edu J. 2022; 7 (1):15-19.
Received: October 25, 2019
Revised: November 27, 2019
Accepted: February 18, 2020
Published: February 19, 2020
Corresponding author:
Professor Aldo Squassi, Od, PhD
Chair of Preventive and Community Dentistry,
Faculty of Dentistry, University of Buenos Aires,
Buenos Aires, Argentina. Marcelo T. de Alvear 2142,
C1122AAH, Buenos Aires, Argentina
Tel/Fax: +54-11-5287-6254, e-mail: asquassi@gmail.com
Copyright: O 2020 the Editorial Council
for the Stomatology Edu Journal.
samples were used to evaluate differences among groups.

Results: Proportion of arrested lesions 1-year post treatment: G1=54.5\%, $\mathrm{G} 2=43.4 \%, \mathrm{G} 3=47.4 \%$. No statistical difference was found among groups $(p<0.05)$. Proportion of lesions remaining active at 1 year showing no caries progression: $\mathrm{G} 1=69 \%, \mathrm{G} 2=80 \%, \mathrm{G} 3=100 \%$. No statistical difference was found among groups $(p<0.05)$.

Conclusion: The three professionally applied fluoride agents showed similar effectiveness in arresting early carious lesions in young permanent teeth 1 year post-application.

\section{KEYWORDS}

Tooth Remineralization; Fluoride Varnishes; Caries Arrest; Preventive Dentistry; Topical Fluorides.

\section{INTRODUCTION}

The conventional treatment of caries lesions has historically focused on the mechanical treatment of the lesion. Such an approach [17] disregards the ecological imbalances in the oral cavity, involves restorations that require replacement and which become larger with time, and can result in tooth loss. Successive investigations have reported findings that support a paradigm shift in the treatment of caries. The "Ecological Plaque Hypothesis" [1415] emphasizes the dynamic relation between the environment and the composition of the oral microbiota. Imbalances in the resident microflora have an impact on the environment, disrupting the demineralization/remineralization balance at the biofilm-enamel interface. When this imbalance continues, the carious lesion becomes visible [7]. Fluoride plays a key role in the prevention and control of dental caries. The cariostatic effect of fluoride can be attributed mainly to its ability to influence ion exchange reactions at the plaque-enamel interface, even at low concentrations (0.2-1 ppm), facilitating calcium and phosphate precipitation [6]. Because of its inorganic composition, saliva contributes to remineralization [10-12]. When fluoride is applied in high concentrations (in vehicles such as varnishes and gels), a calcium fluoride precipitate is produced on the surface of the enamel and in the plaque. This calcium fluoride acts as a temporary storage of fluoride, which is released when the $\mathrm{pH}$ drops [11]. Hence, varnishes and gels deliver fluoride to the 


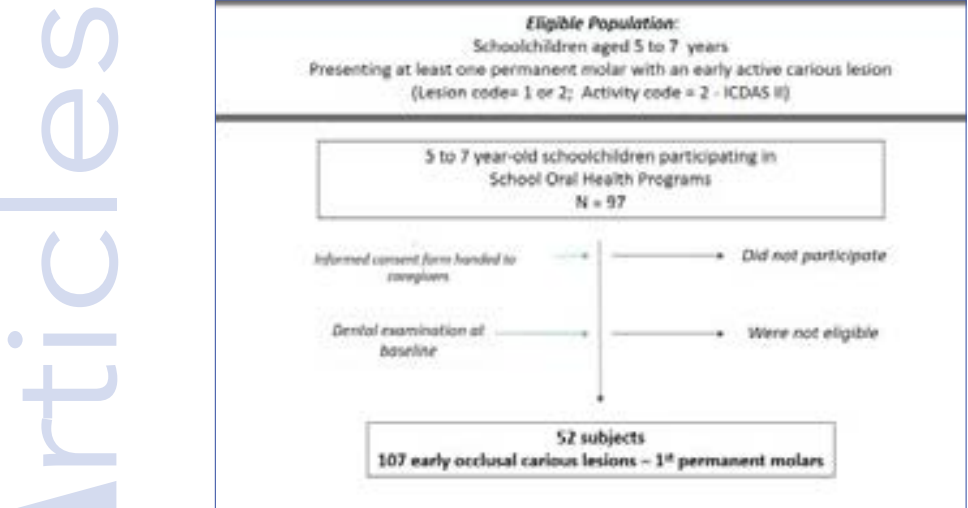

Figure 1. Sampling method.

enamel surface and to the subsurface of carious lesions, where calcium fluoride deposits and acts as a reservoir of fluoride ions [16].The presence of fluoride ions during the demineralization stage guarantees the incorporation of fluoride into the apatite crystals, forming crystalline structures that are more resistant to acid challenge [21]. Fluorides can contribute both to decreasing lesion progression and to arresting or repairing lesions. These effects have been studied in vitro and in situ. A meta-analysis on four studies showed that $5 \%$ sodium fluoride $(\mathrm{NaF})$ varnish remineralized approximately two thirds of caries lesions in children [22]. Different compounds have been added to fluoride varnishes with the aim to achieve improved mineralizing effects. However, addition of chlorhexidine or calcium fluoride has not shown significant clinical benefits [4-8-1]. The addition of $\beta$ tricalcium phosphate ( $\beta$ TCP) to fluoride varnish improved the protective ability of the varnish on primary teeth, based on microhardness readings[2].

Objective: To compare the effectiveness of 3 professionally applied fluorides in arresting incipient carious lesions in young permanent teeth.

\section{MATERIALS AND METHODS}

A quasi-experimental study was conducted. Nonprobability consecutive sampling was used to select participants (Fig.1). A baseline diagnosis was performed to identify eligible subjects. The eligible population comprised schoolchildren aged 5 to 7 years, attending public schools in the city of Buenos Aires, presenting at least 1 permanent molar with activeincipient caries lesion (corresponding to lesion codes 1 and 2 and activity status 2 according to ICDAS II criteria) [20].

The study was conducted within the framework of a dental care program for schoolchildren in suburban neighborhoods, in school settings. Schoolchildren complying with the eligibility criteria and whose legal guardians signed the informed consent form were included in the study.

Fifty-two subjects had at least one early carious lesion in a permanent molar. The final study sample

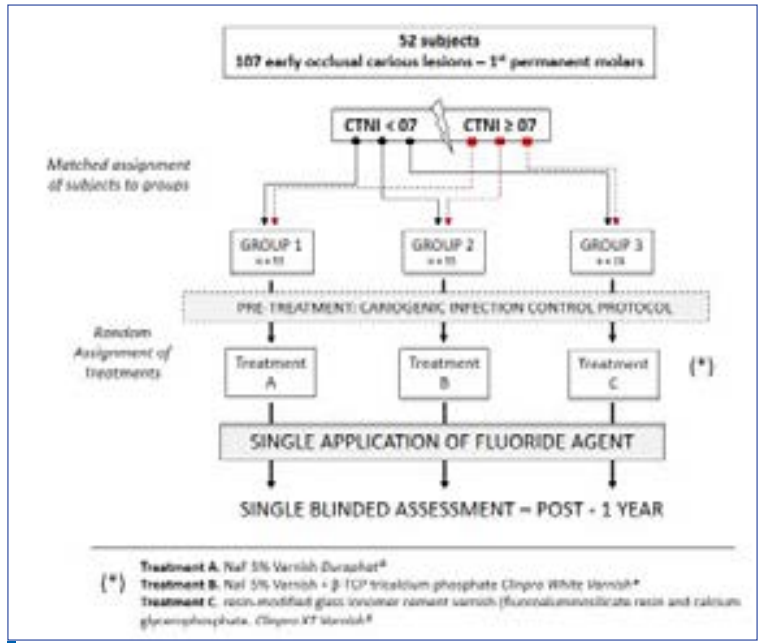

Figure 2. Study design.

comprised 107 tooth surfaces with early occlusal carious lesions.

\subsection{Study design}

The subjects were divided into three groups matched according to the caries treatment needs, which was determined according to the severity of the carious lesion $\left(\mathrm{CTN}^{19} \leq 6-\right.$ no caries lesion involving the pulp; does not require complex treatments / CTNI $\geq 7$ - presence of caries lesion involving the pulp; requires pulp therapy or surgery). The treatments (professionally applied fluoride) were randomly assigned to each group.

Group A: 5\% Sodium Fluoride Varnish (Duraphat ${ }^{\circledR}$ ) Group B: Sodium Fluoride varnish containing $\beta$-TCP tricalcium phosphate (Clinpro White Varnish ${ }^{\circledR}$ )

Group C: Glass ionomer modified with fluoroaluminosilicate resin and calcium glycerophosphate (Clinpro XT Varnish $^{\circledR}$ ). In compliance with the protocol, all subjects received a preventive treatment protocol, which included measures to control factors influencing the biofilm formation and structure, such as biofilm retention sites and active cavitated carious lesions: training and supervision of oral tooth brushing, supragingival scaling in cases presenting calculus, polishing of restorations, and restoration of cavitated carious lesions with no pulpal involvement using an atraumatic restorative technique (ART). Primary and permanent teeth presenting caries lesions with pulpal involvement were endodontically treated or extracted according to the type of pulpal involvement (PUFA index) and size of the tooth remnant, thus determining the subsequent restoration.

The corresponding fluoride was applied on the lesions once, following the manufacturers' instructions. The lesions were assessed one year postfluoride application (simple blinding technique: the examiner was blinded to the treatment allocation of the subjects). The diagnosis and assessment of the lesions were performed by two researchers who were calibrated against a gold standard examiner (Kappa interrater agreement value $>0.8$ ). The statistical 


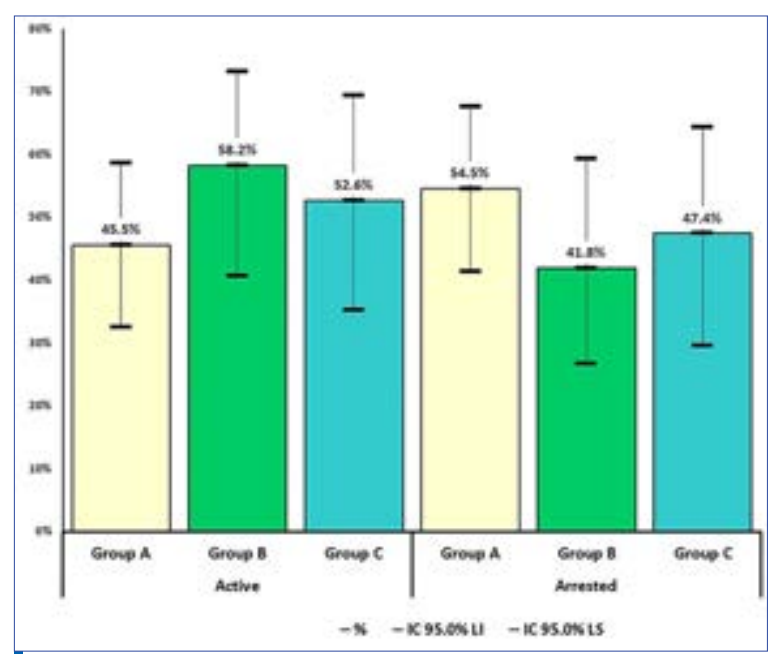

Figure 3. Arrest of early carious lesion 1 year post-treatment.

analysis involved calculating the frequency of (a) early carious lesion remineralization one year posttreatment and of (b) carious lesions that remained active but showed no progression one year posttreatment. The groups were compared using the Chi square test and the comparison of proportions for independent samples. Due to the sample size, a Bootstrap technique was apllied with Montecarlo sampling methods (1000 samples $-95 \% \mathrm{Cl}$ level). A binomial exact test was used to compare groups.

\subsection{Compliance with Ethical Requirements}

The caregivers/legal guardians of the schoolchildren signed an informed consent form authorizing the child's participation in the study. All the schoolchildren who participated in the study gave their assent for the treatment.

The present research work was approved by the ethics committee of the University of Buenos Aires (UBACyT 20020120100324BA).

\section{RESULTS}

The percentage of early carious lesions that became stabilized according to ICDAS II criteria one year post-treatment was $54.5 \%$ in Group 1 (Duraphat ${ }^{\circledR}$ ), $41.8 \%$ in Group 2 (Clinpro White varnish), and $47.4 \%$ in Group 3 (Clinpro XT varnish). No statistically significant differences were observed among groups (Pearson Chi square test: $d f=2 ; p$-value $=0,529$ ). The tests were adjusted for all pairwise comparisons within a row of each innermost subtable using the Bonferroni correction (Fig. 3). As regards the caries progression, $91.4 \%$ of lesions in Group 1, 83.3\% of lesions in Group 2, and $100.0 \%$ of lesions in Group 3 showed no progression, with no significant differences among groups (Pearson Chi square test: $d f=2 ; p$-value $=0,201$ ) (Fig. 4). When considering the sub-set of lesions that remained active one year post-treatment, the percentage of lesions showing no caries progression was $80.0 \%$ in Group 1, 69.0\% in Group 2, and $100.0 \%$ in Group 3; no significant

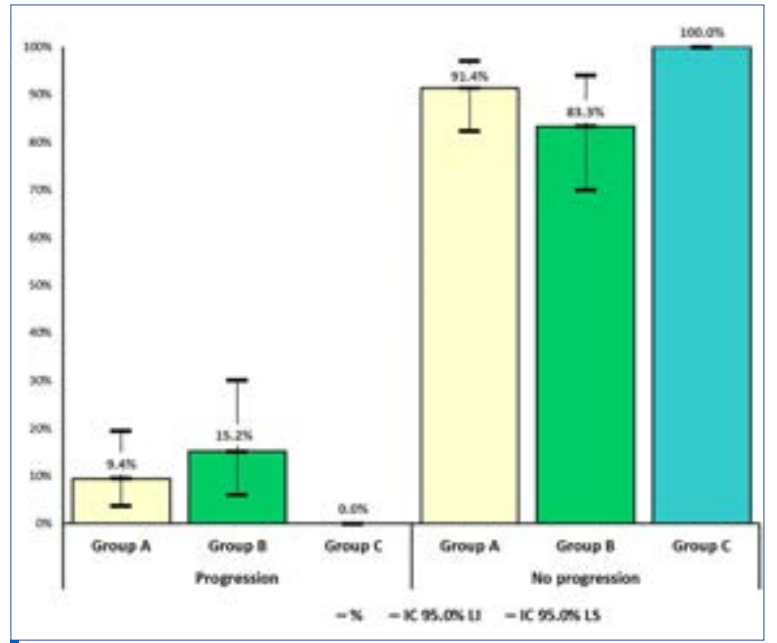

Figure 4. Early carious lesion progression 1 year post-treatment.

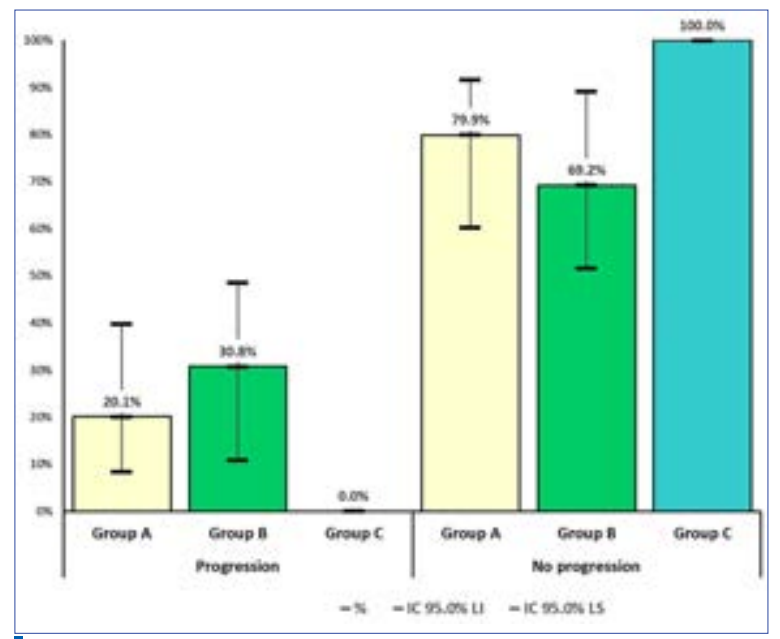

Figure 5. Early carious lesion progression among lesions remaining active 1 year after treatment.

differences were observed among groups (Fig.5). In all cases the tests were adjusted for all pairwise comparisons within a row of each innermost subtable using the Bonferroni correction. In Group C, this category was not used in comparisons because its column proportion is equal to zero or one

After appliyng the Bootstrap technique, no significant differences were found for caries arrest ( $p$ value Exact Test $=0,577$ (CI95\%: 0,544-0,569)); caries progression ( $p$ value Exact Test $=0,225$ (CI95\%:0,214$0,236)$ ); and early carious lesion progression among lesions remaining active ( $p$ value Exact Test $=0,274$ (CI95\%: 0,263-0,286).

\section{DISCUSSION}

The professional application of fluoride varnishes to treat early enamel carious lesions is a noninvasive, easy to use and low cost procedure compared to conventional mechanical treatments. The effectiveness of fluoride varnishes in primary caries prevention has been widely investigated, and recommendations for its use in primary and clinical 


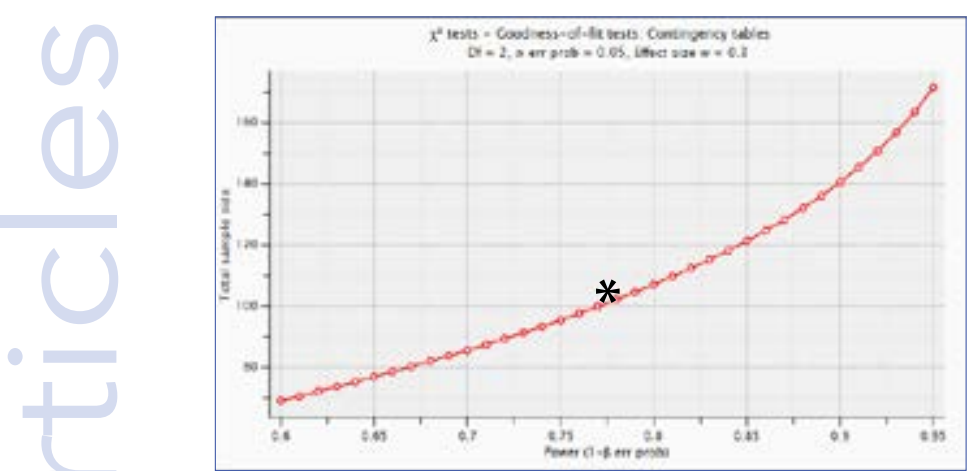

Figure 6. Power analysis.

permanent dentitions are supported by conclusive scientific evidence [18-13]. Nevertheless, few studies have assessed the effect of fluoride on early carious lesions, especially those located in the pit and fissure system. According to a systematic review [22], six clinical trials demonstrated the remineralizing effect of $5 \% \mathrm{NaF}$ varnish. The results of a meta analysis on four of the six clinical trials showed an overall percentage of remineralised enamel caries of $63.6 \%$ (Cl 95\%: 36.0\% - 91.2\%). A number of studies have evaluated early carious lesion remineralization using $5 \% \mathrm{NaF}$ varnish, by measuring the reduction in white spot lesion size 4-8, and determining the percentage of remineralized carious lesions, in a range between $81.2 \%$ and $71.4 \%$ [1-5-3]. The results of the works mentioned above are not comparable with the results of the present study given the differences in the localization of the studied lesions, type of dentition, frequency of application of the varnish, and duration of the studies. The arrest and progression of active incipient occlusal caries in the first permanent molars of six-year old children were analyzed [9]. The results after one year application of $5 \% \mathrm{NaF}$ varnish $\left(\right.$ Duraphat $^{\circledR}$ ) showed remineralization in $83.3 \%$ of lesions and caries progression in $5.5 \%$ of lesions. The results of the present study however, showed $54.4 \%$ caries arrest and $16.7 \%$ progression in the $5 \%$ $\mathrm{NaF}$ treated group. The differences may be due to the characteristics of the studied populations, the setting where the studies were conducted, and the

\section{REFERENCES}

1. Almeida MQ, Costa OXI, Ferreira JMS, et al. Therapeutic potentia of Brazilian fluoride varnishes: an in vivo study. Braz Dent J. 2011;22(3):193-197.

[Full text links] [CrossRef] [PubMed] Google Scholar Scopus

2. Al Amoudi SA, Sharat CP, AlOmari M. The effect of the addition of tricalcium phosphate to $5 \%$ sodium fluoride varnishes on the microhardness of enamel of primary teeth. Int $J$ Dent. 2013;2013:486358.

[Full text links] [CrossRef] [PubMed] Google Scholar Scopus

3. Autio-Gold JT, Courts F. Assessing the effect of fluoride varnish on early enamel carious lesions in the primary dentition. J Am Dent Assoc. 2001;132(9):1247-1253; quiz 1317-1318. [Full text links] [CrossRef] [PubMed] Google Scholar Scopus

4. de Amorim RG, Leal SC, Bezerra AC, et al. Association of chlorhexidine and fluoride for plaque control and white spot lesion remineralization in primary dentition. Int $J$ Paediatr Dent. 2008;18(6):446-451.

[Full text links] [CrossRef] [PubMed] Google Scholar Scopus

5. Du M, Cheng N, Tai B, et al. Randomized controlled trial on fluoride varnish application for treatment of white spot lesion after fixed orthodontic treatment. Clin Oral Investig. 2012;16(2):463-468.

[Full text links] [CrossRef] [PubMed] Google Scholar Scopus diagnostic criteria applied in each study. The work presented here is the first in vivo study on carious lesion arrest using a fluoride varnish containing $\beta$-TCP tricalcium phosphate. Other studies evaluated the effectiveness of professional application of fluoride varnishes containing calcium fluoride $(6 \%$ Difluoride $\mathrm{XII}^{\oplus}$ ) on remineralization of white spot lesions in permanent anterior teeth, and found no differences compared to lesions treated with $5 \%$ $\mathrm{NaF}$ varnish [8-1]. In the present work, goodnessof-fit was lower than 0.8 . Further studies using a larger sample size to decrease the probability of a beta error are necessary (Fig.6). As a strength of this study, we consider that it contributes to the current knowledge on the effectiveness of different fluoride varnishes in arresting early occlusal carious lesions in young permanent molars. The results presented here may prove relevant to decision making in the private practice setting as well as in public health care programs.

\section{CONCLUSION}

The three fluorides studied here showed similar effectiveness in arresting early carious lesions in young permanent teeth one year after application.

\section{CONFLICT OF INTEREST}

The authors declare no conflict of interest.

\section{AUTHOR CONTRIBUTIONS}

GLK: Data analysis, Manuscript drafting, CC and MT: Data gathering, Data interpretation, PAS: Data interpretation, Data analysis, AFS: Protocol design, Data interpretation, Manuscript revision.

\section{ACKNOWLEDGEMENTS}

The authors thank to Municipalidad de Tigre and Universidad de Buenos Aires (Grant UBACYT 20020120100324BA).

6. Fejerskov $\mathrm{O}$. Changing paradigms in concepts on dental caries: consequences for oral health care. Caries Res. 2004;38(3):182-191. [Full text links] [CrossRef] [PubMed] Google Scholar Scopus

7. Fejerskov O, Nyvad B, Kidd E. A. M. Pathology of dental caries. In: Fejerskov O, Kidd E (ed). Dental caries - The disease and its clinical management. 2nd ed. Oxford: Blackwell Munksgaard; 2008. Chap. 3 8. Ferreira JMS, Aragão AKR, Rosa ADB, et al. Therapeutic effect of two fluoride varnishes on white spot lesions: a randomized clinical trial. Braz Oral Res. 2009;23(4):446-451.

[Full text links] [CrossRef] [PubMed] Google Scholar Scopus

9. Flório FM, Pereira AC, Meneghim Mde C, Ramacciato JC. Evaluation of non-invasive treatment applied to occlusal surfaces. ASDC J Dent Child. 2001;68(5-6):326-331, 301.

[PubMed] Google Scholar Scopus

10. Hall AF, Buchanan CA, Millett DT, et al. The effect of saliva on enamel and dentine erosion. J Dent. 1999;27(5):333-339.

[CrossRef] [PubMed] Google Scholar Scopus

11. Horowitz AM. Introduction to the symposium on minimal intervention techniques for caries. J Pub Health Dent. 1996;56(3):133-134.

[Full text links] [CrossRef] [PubMed] Google Scholar Scopus 
12. Imfeld T. Prevention of progression of dental erosion by professional and individual prophylactic measures. Eur J Oral Sci. $1996 ; 104(2(P t 2)): 215-220$.

[Full text links] [CrossRef] [PubMed] Google Scholar Scopus

13. Marinho VC, Worthington HV, Walsh T, Clarkson JE. Fluoride varnishes for preventing dental caries in children and adolescents. Cochrane Database Syst Rev. 2013;(7):CD002279. [CrossRef] [PubMed] Google Scholar Scopus

14. Marsh PD. Are dental diseases examples of ecological catastrophes? Microbiology. 2003;149(Pt 2):279-294.

[CrossRef] [PubMed] Google Scholar

15. Marsh PD. Dental plaque as a biofilm and a microbial community - implications for health and disease. BMC Oral Health. 2006;6(Suppl 1):S14.

[Full text links] [CrossRef] [PubMed] Google Scholar Scopus 16. Øgaard B, Ten Bosch JJ. Regression of white spot enamel lesions. A new optical method for quantitative longitudinal evaluation in vivo. Am J Orthod Dentofacial Orthop. 1994;106(3):238-242.

[Full text links] [CrossRef] [PubMed] Google Scholar Scopus

17. Peters MC. Strategies for noninvasive demineralized tissue repair. Dent Clin North Am. 2010;54(3):507-525.

[Full text links] [CrossRef] [PubMed] Google Scholar Scopus

18. Petersen PE, Lennon MA. Effective use of fluorides for the prevention of dental caries in the 21st. century: the WHO approach. Community Dent Oral Epidemiol. 2004;32(5):319-321.

[Full text links] [CrossRef] [PubMed] Google Scholar Scopus

19. Piovano S, Squassi A, Bordoni N. [Dental caries index: state of the art.] Rev Fac Odontol. (Univ Buenos Aires). 2010;25(58):29-43. [Article in Spanish]

20. Pitts NB. Modern concepts of caries measurement. J Dent Res. 2004;83 Spec No C:C43-C47.

[Full text links] [CrossRef] [PubMed] Google Scholar Scopus

21. Rošin-Grget K, Peroš K, Šutej I, Bašić K. The cariostatic mechanisms of fluoride. Acta Med Acad. 2013;42(2):179-188.

[CrossRef] Google Scholar Scopus

22. Shiqian Gao S, Zhang S, Lei Mei M, et al. Caries remineralisation and arresting effect in children by professionally applied fluoride treatment - a systematic review. BMC Oral Health. 2016;16:12.

[Full text links] [CrossRef] [PubMed] Google Scholar Scopus

\section{Graciela Liliana KLEMONSKIS \\ DDS, PhD, Associated Professor \\ Chair of Preventive and Community Dentistry \\ Faculty of Dentistry \\ University of Buenos Aires \\ Buenos Aires, Argentina}

Graciela Liliana Klemonskis studied dental medicine at the Faculty of Dentistry, University of Buenos Aires, where she obtained her DDS. After graduation, she pursued her professional training and attended a Master's Program in Public Health (MSc) at the same university. That program focused on Oral Health Systems and Services Management. She went on to get her PhD in Dentistry, specializing in Epidemiology and Public Health. Dr Klemonskis is also a Researcher member at Institute of Public Health Research, University of Buenos Aires.

Teaching areas: oral epidemiology; community dentistry; strategic planning; oral health systems and services.

\section{Regarding this study...}

\section{1.... the final sample comprised:}

a. 107 tooth surfaces with early occlusal carious lesions;

bb. 52 tooth surfaces with early occlusal carious lesions;

口c. 94 tooth surfaces with early occlusal carious lesions;

d. 45 tooth surfaces with early occlusal carious lesions.

\section{2.... the proportion of arrested lesions 1-year post treatment was:}

$\square$ a. less than $50 \%$ in the three groups with no statistical difference among groups;

b. over $50 \%$ in the three groups with no statistical difference among groups;

ac. over $40 \%$ in the three groups with no statistical difference among groups;

$\square$ d. less than $40 \%$ in the three groups with no statistical difference among groups.

\section{3. ... the proportion of lesions showing progression 1-year post treatment was:}

a. less than $20 \%$ in the three groups with no statistical difference among groups;

b. over $10 \%$ in the three groups with no statistical difference among groups;

ac. over $80 \%$ in the three groups with no statistical difference among groups;

d. less than $10 \%$ in the three groups with no statistical difference among groups.

\section{4. ...subjects within experimental groups were matched according:}

$\square$ a. caries experience;

b. caries treatment needs;

ac. presence of restorations ;

ad. age. 